\title{
Dinâmica socioambiental na Vila dos Pescadores (Amazônia Oriental, Pará, Brasil)
}

\section{Social and environmental dynamic in the coastal Fishing Village (Eastern Amazonian, Pará, Brazil)}

\author{
Luci Cajueiro Carneiro PEREIRA* \\ Pedro Walfir M. Souza FILHO** \\ Marcilenia de Jesus Silva RIBEIRO* \\ Samara Cristina Campelo PINHEIRO* \\ Zélia Maria Pimentel NUNES* \\ Rauquírio Marinho da COSTA*
}

\section{RESUMO}

\begin{abstract}
Este trabalho descreve os aspectos sociais, econômicos e ambientais de uma comunidade de pescadores (Vila dos Pescadores), situada no estuário do Rio Caeté, no nordeste do Pará (Brasil). A metodologia adotada neste estudo foi baseada em entrevistas, questionários e observação direta para caracterizar alguns aspectos sociais, econômicos e ambientais, bem como no monitoramento de perfis de praia, para determinar a dinâmica costeira local. Os resultados mostram que a maioria dos entrevistados tem entre 18 e 35 anos (50,97\%), são pescadores $(62,13 \%)$, casados $(68,93 \%)$, com $1^{\circ}$ grau incompleto (77,67\%), moram com a família (2-4 pessoas, $39,8 \%)$, em casa própria $(86,89 \%)$ e ganham menos de 1 salário mínimo (95,63\%). A maioria habita a vila há 3 anos ou mais $(42,71 \%)$ e não está satisfeita com a atual situação social, econômica e ambiental. A vila apresenta alguns problemas ambientais, como erosão costeira, e sérios problemas de serviços e infra-estrutura (p. ex. transporte público, telefones públicos, coletores de lixo, iluminação pública, água potável, saneamento básico, comércio, área para lazer, posto de saúde, estacionamento, salva-vidas, escolas, etc.). A ausência de emprego favorece que a pesca seja a principal atividade econômica da vila. Por outro lado, a natureza exuberante, o clima equatorial, a tranquiilidade e a abundância de peixes são aspectos positivos segundo a opinião dos entrevistados.

Palavras-chave: aspectos sociais; aspectos ambientais; comunidade de pescadores; litoral amazônico.
\end{abstract}

\footnotetext{
* Laboratório de Oceanografia Costeira e Estuarina, Campus Universitário de Bragança, Universidade Federal do Pará, Aldeia, CEP: 68600-000, Bragança, Pará, Brasil Fone: (91)3425-4536. cajueiro@ufpa.br

** Laboratório de Análise de Imagens do Trópico Úmido (LAIT), Centro de Geociências, Universidade Federal do Pará, Av. Augusto Correa 1, Guamá, CEP: 66075-110, C.P. 8608, Belém, Pará, Brasil. Fone: (91) 3201-8009. walfir@ufpa.br
} 


\begin{abstract}
This study describes the social, economic and environmental aspects of a fishing community "Vila dos Pescadores" situated in the Caeté River Estuary, northeastern Pará (Brazil). The methodology adopted in this study was based on interviews, questionnaires and direct observations to characterize some social, economic and environmental aspects and on monitored of beach profile to know the local coastal dynamic. Results show that the majority of the interviewed are between $18-35$ years $(50.97 \%)$, are fishermen $(62.13 \%)$, married (68.93\%), with elementary school not completed (77.67\%), live with the family (2-4 persons, $39.85 \%$ ) in their own houses (86.89\%) and earn monthly less than one salary $(95.63 \%)$. The majority of the people has been living in the village for 10 years or more $(42.71 \%)$ and do not like their current social, economic and environmental situation. The village has some environmental problems such as coastal erosion and serious service and infrastructure problems (e.g. little or total absence of public transports, public telephones, garbage collectors, public illumination, drinking water, basic sanitary facilities, underdeveloped commercial area, sport area, health post, police post, car parking, lifeguard, school, among others). The absence of employment opportunities is another problem, being the fisheries the main source of income in the village. On the other hand, the exuberant nature, the equatorial weather, the tranquility and the large amount of fish are the main positive aspects according to the opinion of those interviewed.

Key-words: social aspects; environmental aspects; fishing community; Amazonian littoral.
\end{abstract}

\section{Introdução}

Na região norte do Brasil, as comunidades costeiras rurais sobrevivem principalmente da pesca, que é uma atividade complexa relacionada, culturalmente, às técnicas tradicionais (DIEGUES, 1996). No estado do Pará, considerando sua localização, a pesca pode ser: flúvio-lacustre, costeira e de alto mar. As duas primeiras estão acessíveis aos pequenos pescadores (pesca artesanal/comercial e de subsistência) e a última, à pesca industrial (CABRAL, 1999). Os pescadores da Planície Costeira Bragantina praticam a pesca industrial e artesanal e utilizam, normalmente, como ferramentas de captura o espinhel, anzol, redes e currais. A pesca industrial é responsável pelo abastecimento de peixe em vários municípios da região (Bragança e municípios vizinhos), bem como em outros estados (p. ex. Maranhão, Ceará, Brasília, Rio de Janeiro e São Paulo) e países (Japão, EUA, etc.) (BRAGA, 2002).

Por outro lado, a qualidade e a potencialidade dos recursos pesqueiros na região bragantina são determinadas pelas características físicas (p. ex. relevo e batimetria), biológicas (produtividade) e temporais (período seco e chuvoso) (DIAS NETO; MESQUITA, 1988).

A Vila dos Pescadores, localizada à margem esquerda do rio Caeté, no nordeste do estado do Pará (Figura 1) é caracterizada por migrações de populações que vivem da pesca artesanal costeira (MANESCHY, 1995; KRAUSE; GLASER, 2003; GLASER, 2003), condicionada ao fenômeno natural das macromarés que avançam sobre o continente, principalmente, nos meses de março/abril e setembro/outubro (marés equinociais de sizígias), quando ocorrem as maiores perdas de sedimentos e destruição de edificações (SOUZA-FILHO, 2001; SOUZA-FILHO et al., 2003; SOUZA-FILHO; PARADELLA, 2003).

Para conhecer a dinâmica socioambiental na vila em estudo foram realizados entrevistas, questionários e observação direta com a finalidade de definir o perfil social, os tipos de usos e ocupações territoriais, a atividade pesqueira e a opinião/percepção e as necessidades/preferências dos pescadores em relação ao ambiente, tipos de facilidades (infra-estrutura, acesso e serviço) e níveis de desenvolvimento. Por outro lado, para conhecer a dinâmica costeira local foram monitorados perfis de praia durante o período de um ano.

\section{Área de estudo}

A Planície Costeira Bragantina (NE - Pará) está localizada na faixa costeira do município de Bragança, que se estende da Ponta do Maiaú até a foz do rio Caeté, no 
maior e mais bem preservado ambiente tropical úmido do planeta, a região Amazônica (Figura 1). A Vila dos Pescadores está localizada à margem esquerda do rio Caeté, a 36 km por estrada da sede do município de Bragança.

O clima da área é equatorial quente e úmido (Amw', de acordo com a classificação de Köppen), caracterizado por uma estação muito chuvosa, entre os meses de dezembro e maio, e uma estação seca, nos demais meses do ano. A pluviosidade média anual é de $2.500 \mathrm{~mm}$. A umidade relativa do ar varia entre 80 e $91 \%$. A temperatura média é de $27,7^{\circ} \mathrm{C}$, mas pode variar de 20,4 a $32,8^{\circ} \mathrm{C}$ (MARTORANO et al., 1993).
A costa bragantina é tectonicamente do tipo trainling edge coast (INMAN; FILLOUX, 1960), com topografia plana e ampla plataforma continental, sendo caracterizada pela ação de macromarés, com altura variando de 4 a 6 m (DHN, 2003).

A vegetação predominante na região é a de mangue, formada pelas espécies Rhizophora mangle, Avicennia germinans e Laguncularia racemosa (KRAUSE et al., 2001).

A população que habita a vila em estudo é formada, principalmente, por pescadores com baixo poder aquisitivo. A vila carece de serviços e infra-estruturas básicas, $\mathrm{p}$. ex. saneamento básico, água potável, escolas e melhor acesso (KRAUSE et al., 2000).

FIGURA 1 - MAPA DE LOCALIZAÇÃO E DOS AMBIENTES COSTEIROS DA ÁREA EM ESTUDO (SOUZA FILHO et al., 2003)

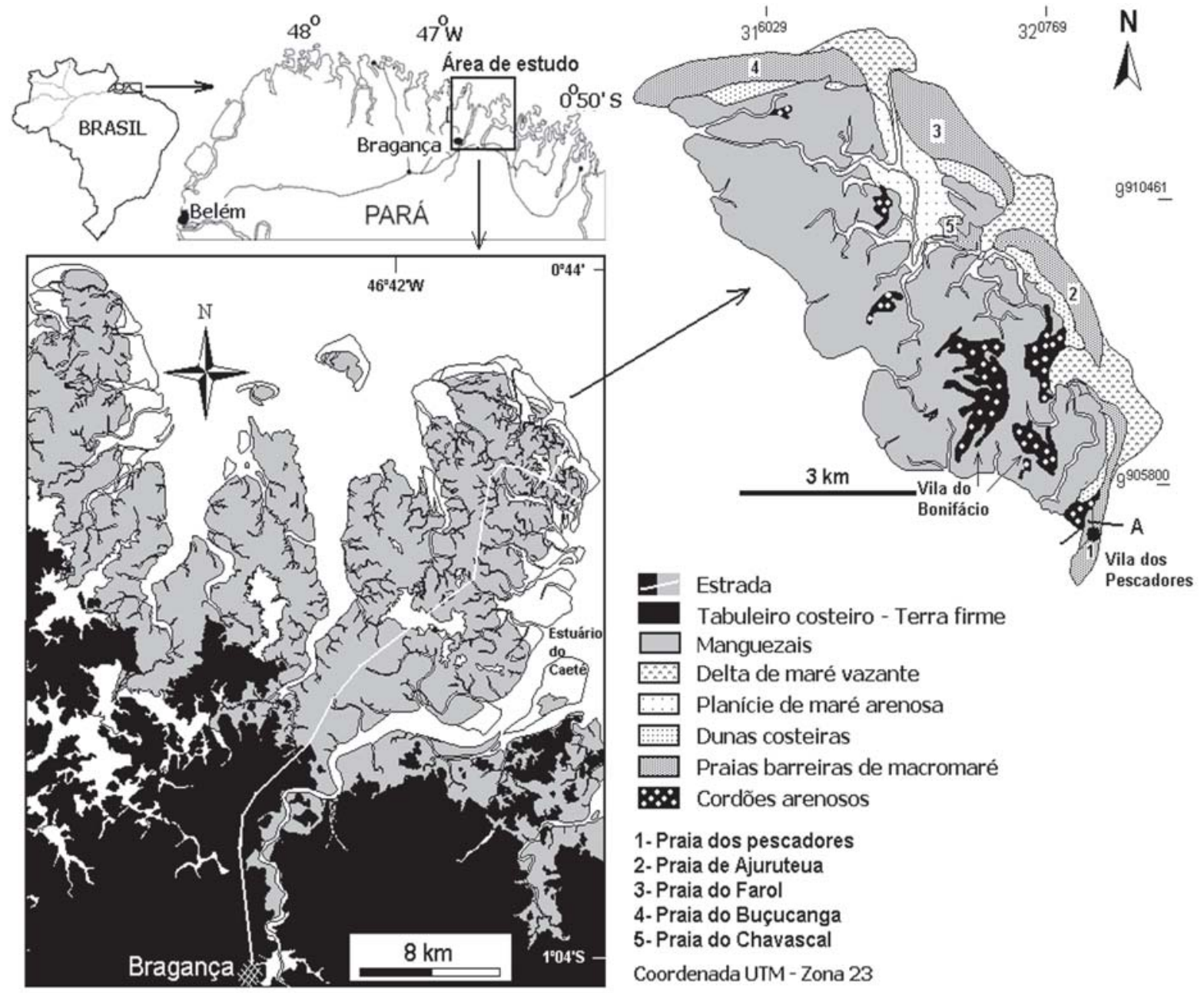




\section{Metodologia}

Para conhecer a dinâmica socioambiental da Vila dos Pescadores, o trabalho foi dividido em cinco etapas: (i) definir o perfil dos moradores, (ii) caracterizar os processos de erosão costeira e a ocupação territorial, (iii) determinar a dinâmica da atividade pesqueira local e (iv) conhecer a opinião e a percepção dos moradores sobre os principais problemas socioambientais.

O perfil dos moradores foi definido a partir do levantamento dos seguintes parâmetros: sexo, idade, estado civil, naturalidade, escolaridade e renda. As entrevistas foram realizadas com uma pessoa de cada residência, que informou os dados dos demais moradores. No total, 206 pessoas foram entrevistadas.

Foi realizado um levantamento sobre o uso dos recursos naturais e ocupação territorial (p. ex. ações antrópicas, áreas de riscos, ordenamento territorial, tipos de infra-estrutura, serviços, etc.), a partir de observação direta e aplicação de questionários. Os questionários seguiram a metodologia de "check list" aplicada por Pereira et al. (2003) e adaptada à realidade local.

Os perfis topográficos foram realizados para caracterizar o estado erosivo da praia da Vila dos Pescadores. Para tal, utilizou-se um nível topográfico, uma mira graduada escalonável de $4 \mathrm{~m}$ e um tripé. As medidas foram realizadas do zero relativo, como nível de referência (E0) relacionado ao nível de maré alta de sizígia de setembro de 1998, a partir do qual foram realizadas leituras sucessivas desde o campo de dunas até, aproximadamente, a profundidade de 1,0 $\mathrm{m}$ da linha de maré baixa de sizígia.

Para entender a dinâmica da atividade pesqueira, principal atividade econômica da região, foram realizadas algumas perguntas estruturadas com 104 pescadores locais (ver Quadro 1).

Por fim, para conhecer a opinião e percepção dos moradores sobre os principais problemas socioambientais, foram utilizadas as metodologias aplicadas por Morgan et al. (1993), Williams et al. (1993), Morgan et al. (1995) e Leatherman (1997), adaptadas à realidade local.

\section{Resultados e discussão}

\section{Perfil dos moradores}

Com respeito ao perfil dos moradores que habitam a Vila dos Pescadores, a maioria é do sexo masculino $(69,9 \%)$, com idades compreendidas entre 18 e 35 anos $(50,97 \%)$, casados $(68,93 \%)$, com primeiro grau incompleto $(77,67 \%)$, pescadores $(62,13 \%)$ e recebendo até um salário mínimo $(95,63 \%)$ (Figura 2). O baixo poder aquisitivo, a baixa escolaridade e a característica jovem da população que habita a Vila dos Pescadores foram registrados em 2000 por Krause e Glaser (2003). A maioria dos moradores vive com a família $(90,29 \%)$, em casa própria $(86,9 \%)$, dividindo a casa com 2 a 4 pessoas $(39,8 \%)$, durante um período de residência de 3 anos ou mais $(42,71 \%)$.

A baixa captação de recursos financeiros pelos moradores da Vila dos Pescadores (KRAUSE; GLASER, 2003), bem

\section{QUADRO 1 - PERGUNTAS REALIZADAS AOS PESCADORES DA VILA DOS PESCADORES, BRAGANÇA-PA(BRASIL)}

\begin{tabular}{|l|}
\hline \multicolumn{1}{|c|}{ PERGUNTAS FEITAS AOS PESCADORES } \\
\hline 1. Quantos dias saem para pescar durante a semana? \\
2. Qual o período em que a pesca é mais produtiva e qual a espécie de peixe capturado? \\
3. Quais os locais de pesca? \\
4. Quais as ferramentas utilizadas na captura? \\
5. Qual o peixe mais rentável economicamente? \\
6. Quanto tempo passa embarcado (horas/dias/semanas)? \\
7. Qual o tipo de embarcação utilizada? \\
8. Se é dono ou empregado da embarcação? \\
\hline
\end{tabular}


FIGURA 2 - ASPECTO SOCIAL: SEXO (A), IDADE (B), ESTADO CIVIL (C), ESCOLARIDADE (D), OCUPAÇÃO (E) E SALÁRIO MÍNIMO (F) DOS MORADORES DA VILA DOS PESCADORES (PARÁ-BRASIL)
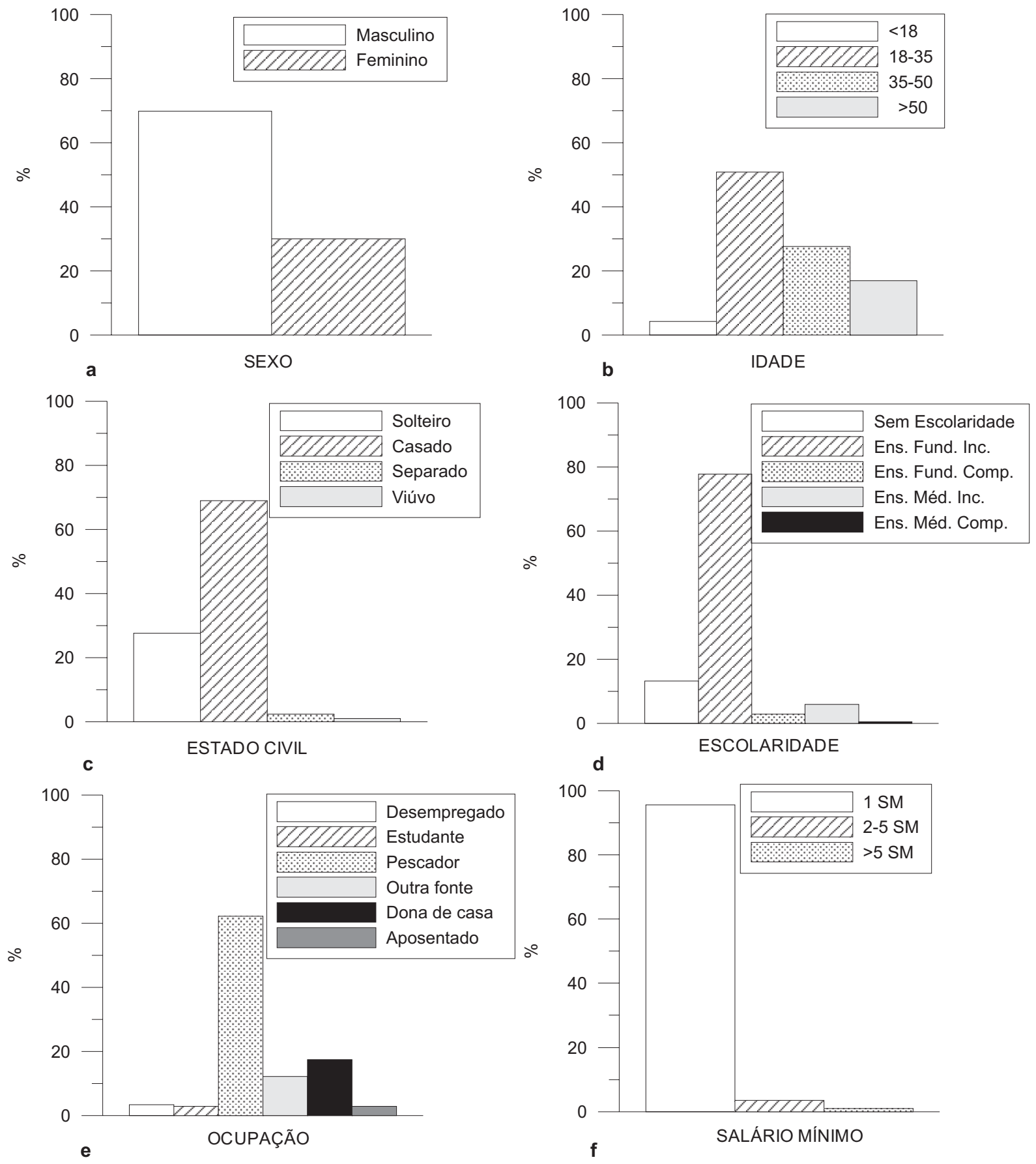
como a baixa escolaridade, torna a população menos exigente, e ela não cobra das autoridades melhores serviços e infra-estrutura. Na Vila existem poucas opções de emprego, sendo a maioria dos homens pescadores ou pequenos comerciantes, trabalhando em mercearias e bares. Para as mulheres quase não existe emprego, e a maioria delas é donas de casa. O baixo nível organizacional dos moradores e até mesmo dos pescadores contribui para a baixa qualidade de vida da população estudada.

\section{Facilidades (acessos, serviços e infra-estrutura)}

$\mathrm{O}$ acesso à Vila dos Pescadores pode ser feito por água (Oceano Atlântico e Rio Caeté) ou por terra, pela estrada PA-458. Diariamente, circulam ônibus de linha que conectam a Vila dos Pescadores às comunidades vizinhas.

Os serviços públicos ou particulares são muito escassos na Vila. Entre os levantamentos realizados foi possível registrar a ausência de agência bancária, posto de saúde, pousada, lojas (roupas, sapatos, etc.), sistema público de abastecimento de água, sistema de saneamento básico, limpeza pública diária, farmácia, policiamento, salva-vidas, correios, etc. Por outro lado, os únicos serviços oferecidos à população local são: escola pública (uma), igrejas (duas), alguns bares e pequenas mercearias (onde são vendidos alguns tipos de alimentos da cesta básica, bebidas e remédios).

No que diz respeito à infra-estrutura, foi possível observar uma quantidade reduzida de telefones públicos, um campo de futebol e alguns postes de iluminação. Existem alguns poços artesanais rasos, com profundidades não superiores a $5 \mathrm{~m}$, que pertencem a alguns particulares.

A ausência de serviços e de infra-estruturas são os mais sérios problemas encontrados nas comunidades rurais do nordeste do Pará. Resultados similares foram encontrados por Pereira et al. (neste número), na Praia de Ajuruteua, e Silva et al. (neste número), em Bacuriteua, situadas a 2 e 30 $\mathrm{km}$ da Vila dos Pescadores, respectivamente.

\section{Morfologia praial, evolução dos processos erosivos e ocupação territorial}

A Praia da Vila dos Pescadores está inserida no contexto da Planície Costeira de Bragança (souZA FILHo; EL-
ROBRINI, 2000; SOUZA FILHO; PARADELLA, 2002), onde ocorrem manguezais, planícies de marés arenosas, dunas costeiras, cheniers (antigos cordões de dunas e praias envoltos por manguezais), deltas de marés vazantes e praias de macromarés arenosas (Figura 1).

A praia da Vila dos Pescadores apresenta um perfil típico de uma praia de terraço de maré baixa, com as zonas de intermaré superior e média apresentando uma declividade bem superior à da zona de intermaré inferior (Figura 3A). A zona de intermaré (ZI) da praia de macromaré dos Pescadores é a face propriamente dita da praia que ocorre entre os níveis de maré alta e baixa de sizígia. Esta zona foi subdividida em três zonas distintas, cada qual distinguida por diferentes características morfológicas e sedimentológicas, frequiência de inundações e regime dinâmico: (1) Zona de intermaré superior (ZIS), que se limita a partir da linha de maré alta de quadratura (LMAQ) até a linha de maré alta de sizígia (LMAS), em torno de $100 \mathrm{~m}$ de largura; (2) Zona de intermaré média (ZIM), que se estende desde a linha de maré alta de quadratura (LMAQ) até a linha de maré baixa de quadratura (LMBQ), com largura média de $160 \mathrm{~m}$; e Zona de intermaré inferior (ZII), que se estende aproximadamente $450 \mathrm{~m}$ desde a linha de maré baixa de quadratura (LMBQ) até a linha de maré baixa de sizígia (LMBS), totalizando $710 \mathrm{~m}$ de extensão (Figura 3A).

Em direção ao canal de maré (ver Figura 1), o perfil topográfico mostra a presença do canal do Furo da Estiva (Figura 3B), cuja migração em direção à Vila dos Pescadores é responsável por sua progressiva destruição. O monitoramento do perfil topográfico de março de 1998 a janeiro de 1999 mostra um recuo de $12 \mathrm{~m}$ da margem do canal de maré (Figura 3C).

A Vila dos Pescadores é formada por casas de madeira, construídas sobre campos de dunas situadas às margens do Furo da Estiva e da Praia da Vila dos Pescadores (Figura 4). À medida que se dá o recuo da margem do Furo da Estiva, as casas vão sendo desmontadas e transferidas para as porções mais interiores da planície costeira. Atualmente, a Vila dos Pescadores está sendo deslocada para o Chenier - cordão de dunas antigo - onde está-se instalando a Vila do Bonifácio (Figura 1).

Comparando os dados de Maneschy (1985) e Krause e Glaser (2003), observou-se que durante uma década houve uma redução de $60 \%$ no número de casas na Vila dos Pescadores (300 casas em 1987 e 119 casas em 1997). Atualmente existem pouco menos de 100 casas. 
FIGURA 3 - MORFOLOGIA DA PRAIA DOS PESCADORES (A), DA MARGEM DO CANAL DE MARÉ ADJACENTE AO FURO DA ESTIVA (B) E RECUO DA MARGEM DO CANAL DE MARÇO DE 1998 A JANEIRO DE 1999 (C)
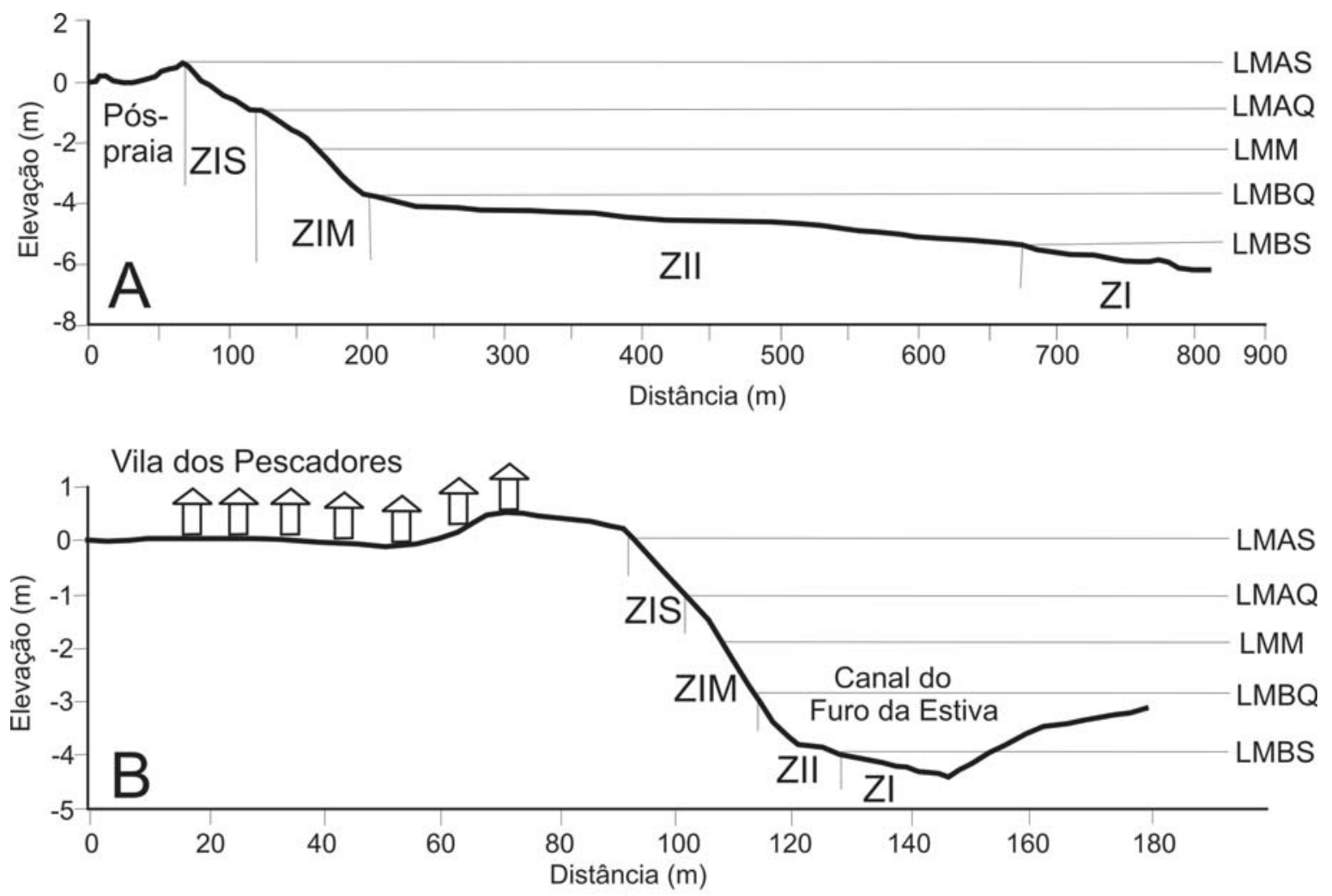

LMAS - Linha de maré alta de sizígia

LMAQ - Linha de maré alta de quadratura

LMM - Linha média das marés

LMBQ - Linha de maré baixa de quadratura

LMBS - Linha de maré baixa de sizígia

ZIS - Zona de intermaré superior ZIM - Zona de intermaré média ZII - Zona de intermaré inferior ZI - Zona de inframaré

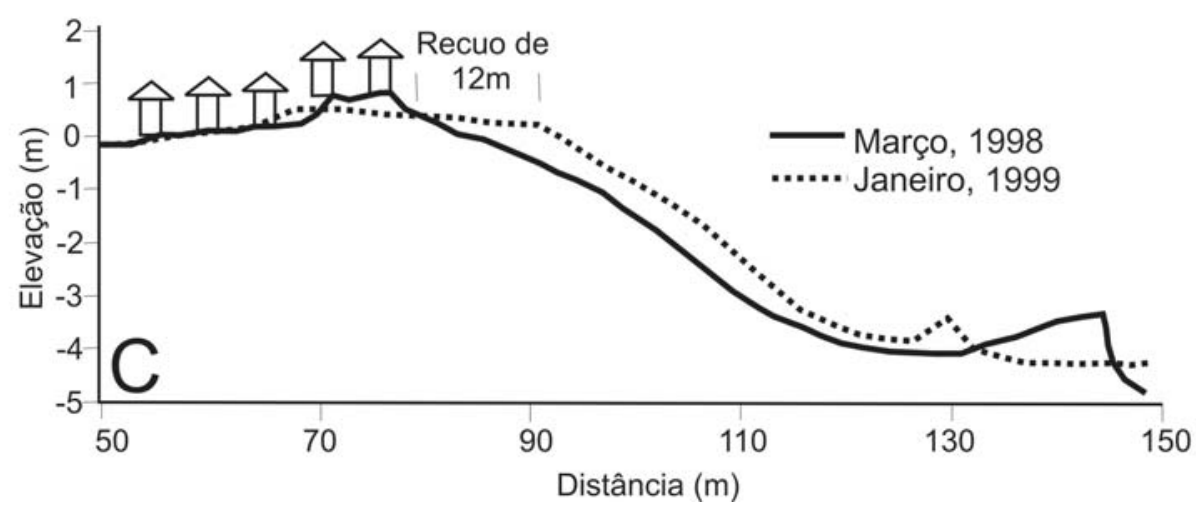




\section{FIGURA 4 - A) EROSÃO NA PRAIA DOS PESCADORES}

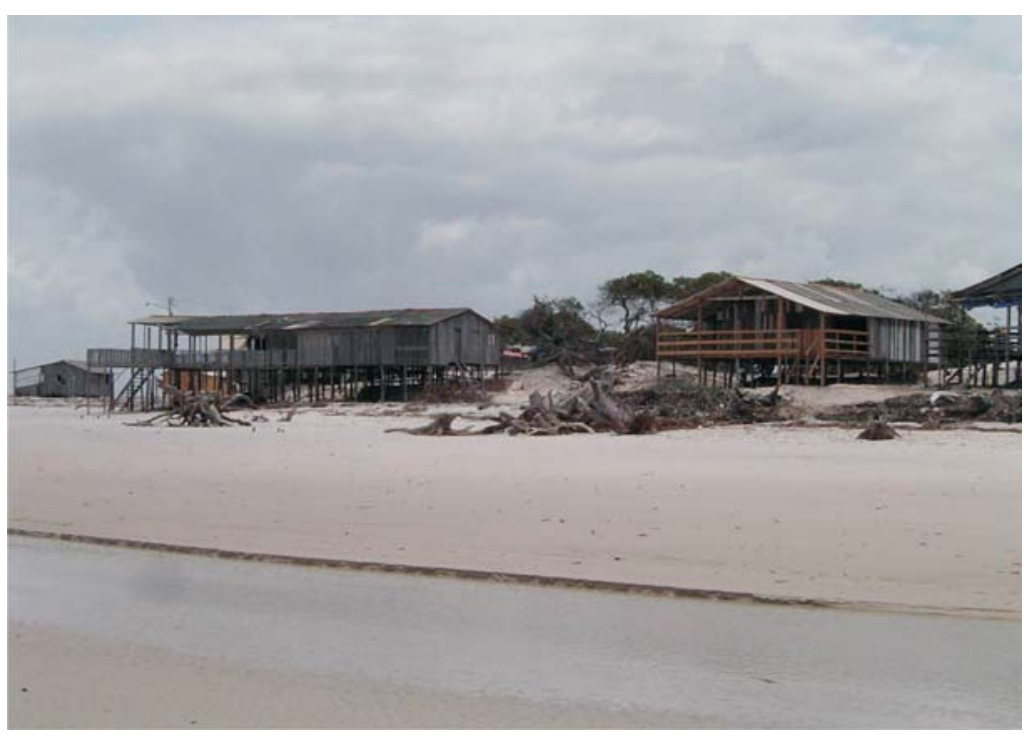

B) EROSÃO NAS MARGENS DO FURO DAESTIVA

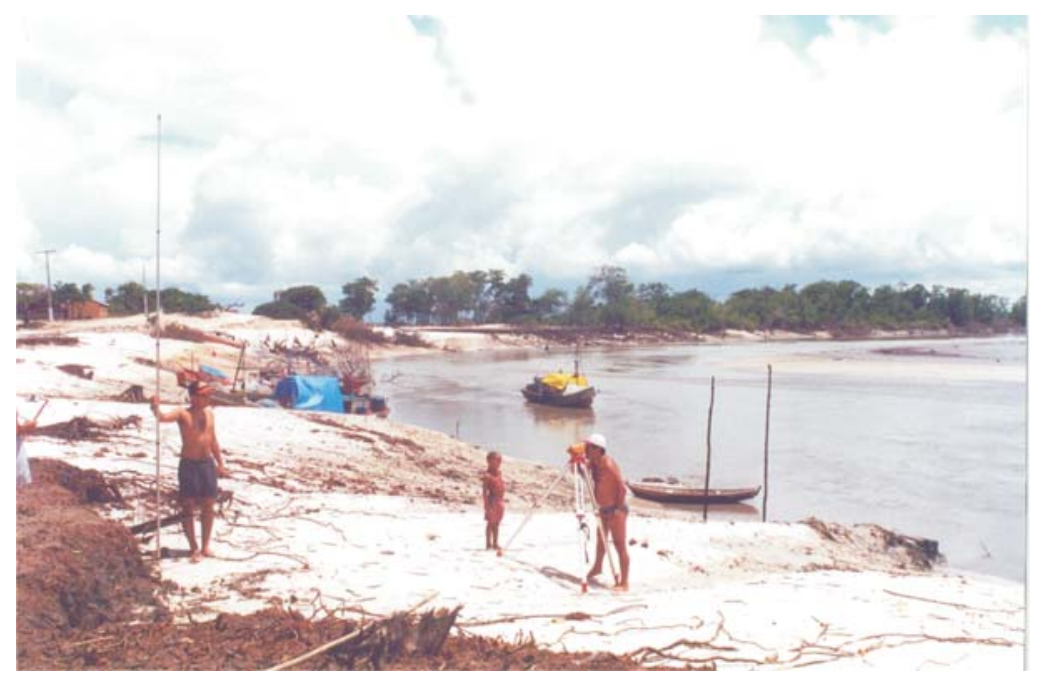




\section{C) TIPO DE CONSTRUÇÃO E OCUPAÇÃO SOBRE CAMPOS DE DUNAS NA VILADOS PESCADORES}

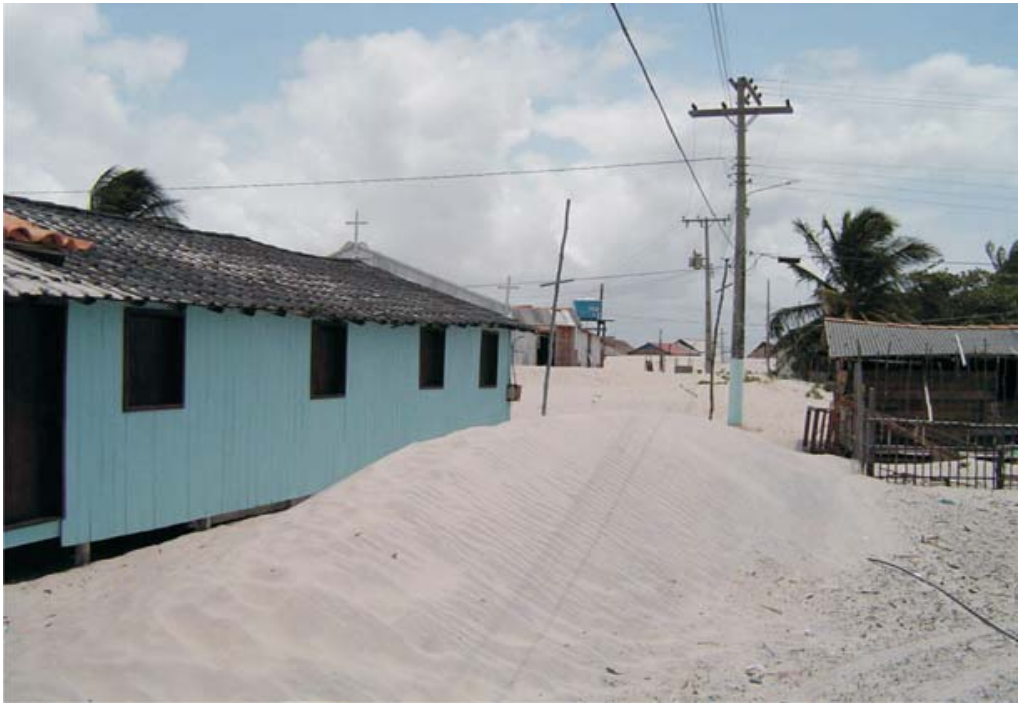

\section{Atividade pesqueira}

A Vila dos Pescadores está localizada em uma região com abundância de peixes e de natureza exuberante. Essas características são responsáveis por atrair pescadores de várias cidades do norte e nordeste brasileiro que procuram esta vila como uma opção de moradia e trabalho.

Com relação à pesca, a maioria dos entrevistados $(55,77 \%)$ respondeu que vai pescar todos os dias da semana. A melhor época de embarque (em relação às condições hidrodinâmicas) é durante o período seco, mas é no período chuvoso que a pesca é mais produtiva, principalmente entre os meses de janeiro a junho (meses de safra), durante as marés de sizígia. A pesca artesanal é a predominante e representa uma das principais atividades econômicas da Vila dos Pescadores. Resultados similares foram registrados por Krause e Glaser (2002) no ano de 2000.

De acordo com os entrevistados, o local mais procurado para a pesca é fora da baía do Caeté $(36,54 \%)$, mas alguns pescadores $(10,5 \%)$ não têm um lugar definido.

O produto pescado serve, principalmente, para o consumo de subsistência e venda (65,38\%). Durante o período de safra, cada barco pesca por semana de 100 a $500 \mathrm{~kg}$ de peixe $(48,08 \%)$, dependendo do tamanho da embarcação.
Os tipos de ferramentas mais utilizados são a rede $(49,04 \%)$ e o espinhel $(9,62 \%)$. As saídas podem durar algumas horas $(24,1 \%), 24$ horas $(37,5 \%)$, ou de 5 a 10 dias $(10,5 \%)$.

Entre os peixes capturados, os mais rentáveis economicamente são Macrodon ancylodon (pescada gó) e Cynoscion acoupa (pescada amarela), segundo 89,43\% dos entrevistados. Os tipos de embarcações mais empregados são o barco a motor $(63,46 \%)$ e a canoa $(25,96 \%)$. Entre os entrevistados, 42,31\% são os donos das embarcações e $44,23 \%$ os empregados, os demais são sócios ou trabalham em embarcações emprestadas.

De acordo com Espírito Santo et al. (2005), na pesca artesanal da região bragantina destacam-se as malhadeiras (captura da pescada amarela), rede de arrasto, currais (captura da pescada gó) e puçás.

\section{Opinião e percepção dos moradores}

De acordo com a opinião e percepção dos moradores sobre a qualidade de vida e qualidade ambiental da vila em estudo, foi observado que a abundância de peixe é o que existe de melhor (44,6\%), seguida pelo clima (12,6\%). Por outro lado, na vila existem vários problemas que foram 
mencionados como aspectos negativos: falta de água potável $(29,6 \%)$, erosão $(9,7 \%)$, falta de peixe no verão $(7,3 \%)$, falta de saneamento básico $(5,3 \%)$, presença de dunas $(5,3 \%)$, etc.

Embora seja considerada um aspecto positivo por parte dos entrevistados, a abundância de peixes não é, necessariamente, sinônimo de poder aquisitivo, pois mesmo sendo proprietário de parte dos seus meios de trabalho, suas condições de vida são muito limitadas e estes equipamentos estão longe de lhes propiciar autonomia, segundo Maneschy (1995).

Entre os principais problemas ambientais verificados por Souza-Filho em 2001, os processos erosivos foram os responsáveis pela destruição de mais de $500 \mathrm{~m}$ da vila, voltados para o canal estuarino, nos últimos 20 anos. Estudos realizados por Krause e Glaser (2003) revelam que a consequiência dos processos erosivos é a destruição da vegetação (mangue e frutíferos) e o deslocamento de muitas famílias com suas respectivas casas (construção de madeira) em busca de áreas mais protegidas p. ex.Vila do Bonifácio, localizada a, aproximadamente, $2 \mathrm{~km}$ da Vila dos Pescadores (Figura 1). Durante as marés de sizígia, principalmente as equinociais de sizígia, as águas do estuário do rio Caeté alagam mais de $70 \%$ da vila. Neste período, os riscos de contrair doenças aumentam, por causa da escassez de infra-estrutura, p. ex. dispersão de lixo por falta de coletores. O problema se agrava pela falta de serviços, como saneamento básico, limpeza pública periódica e água potável.

Com relação à falta de serviços, a água potável é um bem relativamente raro na Vila dos Pescadores, que é abastecida apenas por águas de poços comunitários, do qual os moradores, principalmente as mulheres, carregam incansáveis baldes para suas necessidades básicas (FURTADO;
NASCIMENTO, 1982). Por fim, nem todas as casas apresentam fossas, sendo os dejetos lançados in natura em uma pequena vala localizada abaixo de suas casas.

\section{Conclusões}

A pesca artesanal predomina na região e representa a principal atividade econômica da vila. Durante o período de estudo foram registrados vários problemas de caráter social e ambiental na Vila dos Pescadores. Entre os problemas sociais, foi possível registrar que a qualidade de vida da população local poderia ser muito melhor se não fosse a ausência ou precariedade de vários tipos de serviços e infraestruturas (p. ex. rede de água potável, rede de saneamento básico, posto de saúde, iluminação, entre outros). Por outro lado, a erosão também é considerada um grave problema para as famílias que vivem às margens do estuário do rio Caeté, próximo à sua desembocadura. Os processos erosivos são resultados da configuração geomorfológica da vila e do intenso movimento das águas, entre outros problemas de caráter antrópico, como a construção das casas sobre os campos de dunas móveis. Planos emergenciais devem ser elaborados para inverter a atual situação.

\section{Agradecimentos}

Este estudo é resultado do Projeto Milênio Recos Uso e Apropriação dos Recursos Costeiros (MCT, Finep, $\mathrm{CNPq}$ ) e Projeto Universal Praias Arenosas de Macromaré (CNPq Proc. \# 473097/2003-6). O segundo autor agradece ao $\mathrm{CNPq}$ pela bolsa de produtividade em pesquisa durante esta investigação (processo CNPq \# 303238/2002-0). 


\section{Referências}

BRAGA, C. F. A atividade pesqueira de larga escala nos portos de desembarque do estuário do Rio Caeté, BragançaPA. 2002. Dissertação (Mestrado em Ecologia de Ecossistemas Costeiros) - Universidade Federal do Pará, Campus de Bragança.

CABRAL, N. Legislação e políticas públicas para a pesca artesanal: o que existe e o que sabem os pescadores. 1999. Monografia (Especialização) - Universidade Federal do Pará.

DHN. Tábua das marés para 2003. Fundeadouro de Salinópolis (Estado do Pará). Disponível em: <http:// www.mar.mil.br/ dhn/tabuas>. Acesso em: 2003.

DIAS NETO, J; MESQUITA, J. X. Potencialidade e exploração dos recursos pesqueiros do Brasil. Ciência e Cultura, v. 5, n. 40, p. 427-441, 1988.

DIEGUES, A. C. S. Ecologia humana e planejamento em áreas costeiras. SP: Nupaub-USP, 1996.

ESPIRITO SANTO, R. V. et al. Peixes e camarões do litoral bragantino. Pará-Brasil. Belém: Madam, 2005.

FURTADO, L. G.; NASCIMENTO, I. H. dos. Pescadores de linha do litoral paraense; uma contribuição aos estudos de campesinado na Amazônia. Boletim do Museu Paraense Emílio Goeldi, Belém, n. 82, p. 1-49, 1982.

GLASER, M. Interrelations between mangrove ecosystem, local economy and social sustainability in Caeté Estuary, North Brazil. Wetlands Ecology and Management, n. 11, p. 265272, 2003.

INMAN, D. L.; FILLOUX, J. 1960. Beach sequence related to tide and local wind wave regime. Journal of Geology, v. 2, n. 68 , p. $225-231,1960$.

KRAUSE, G. et al. Spatial patterns of mangrove ecosystems:the bragantinian mangroves of North Brazil (Bragança, Pará). Ecotropica, n. 7, p. 93-107, 2001.

et al. 2000. Coastal dynamics and socio-economic implications. In: GERMAN-BRAZILIAN WORKSHOP ON NEOTROPICAL ECOSYSTEMS, 2000. Proceedings... 2000. p. 997-1000.

; GLASER, M. Co-evolving geomorphical and socioeconomic dynamics in a coastal fishing village of the Bragança region (Pará, North Brazil). Ocean \& Coastal Management, n. 46, p. 859-874, 2003.
LEATHERMAN, S. P. Beach rating: a methodological approach. Journal of Coastal Research, n. 13, p. 253-258, 1997.

MANESCHY, M. C. Ajuruteua, uma comunidade pesqueira ameaçada. Belém: UFPA, 1995.

MARTORANO, L. G. et al. Estudos climatológicos do Estado do Pará, classificação climática (Köppen) e deficiência hídrica (Thornthwhite, Mather). Belém: Sudam/Embrapa, SNLCS, 1993.

MORGAN, R. et al. Beach user opinions and beach ratings: A pilot study on the Turkish Aegean Coast. In: MEDCOAST '95, 1995, Espanha. p. 373-383.

; JONES, T. C.; WILLIAMS, A. T. Opinions and perception of England and Wales Heritage coast, Wales. Journal of Coastal Research, n. 9, p. 1083-1093, 1993.

PEREIRA, L. C. C. et al. The influence of the environmental status of Casa Caiada and Rio Doce beaches (NE Brazil) on beaches users. Ocean and Coastal Management, n. 46, p. 1011-1030, 2003.

et al. Formas de uso e ocupação na praia de AjuruteuaPará (Brasil). Desenvolvimento e Meio Ambiente: dinâmicas naturais dos ambientes costeiros: usos e conflitos. Neste número.

SILVA, I. R. da; COSTA, R. M.; PEREIRA, L. C. C. P. Uso e ocupação em uma comunidade pesqueira, na margem do estuário do rio Caeté (PA, Brasil). Desenvolvimento e Meio Ambiente: dinâmicas naturais dos ambientes costeiros: usos e conflitos. Neste número.

SOUZA-FILHO, P. W. M. Impactos naturais e antrópicos na planície costeira de Bragança. In: Ecossistemas costeiros: impactos e gestão ambiental. Belém: MPEG, 2001. p. 113-125.

; ELROBRINI, M. Coastal zone geomorphology of the Bragança Area, Northeast of Amazon Region, Brazil. Revista Brasileira de Geociências, v. 3, n. 30, p. 518-522, 2000.

; TOZZI, H. A. M.; EL-ROBRINI, M. Geomorphology, land use and environmental hazard in Ajuruteua macrotidal sandy beach, northeastern, Pará, Brazil. In: KLEIN et al. (Eds.). Brazilian sandy beaches: morphodinamic, ecology, uses, hazards and management. Journal of Coastal Research, n. 35 , p. $580-589,2003$. 
; PARADELLA, W. R. Recognition of the main geobotanical features along the Bragança mangrove coast (Brazilian Amazon Region) from Landsat TM and RADARSAT-1 data. Wetlands Ecology and Management, $\mathrm{n}$. 10, p. 123-132, 2002.

; PARADELLA, W. R. Use of synthetic aperture radar for recognition of coastal geomorphological features, land- use assessment and shoreline changes in Bragança coast, Pará, Northern Brazil. Annals of Brazilian Academy of Sciences, v. 3, n. 75, p. 341-356, 2003.

WILLIAMS, A. T. et al. A psychological approach to attitudes and perception of beach user: implication for coastal zone Management. In: MEDCOAST '93, 1993, Turquia. p. 218228. 